\title{
(6) OPEN ACCESS \\ Thermoregulatory effects of swaddling in Mongolia: a randomised controlled study
}

\author{
Bazarragchaa Tsogt, ${ }^{1}$ Semira Manaseki-Holland, ${ }^{2}$ Jon Pollock, ${ }^{3}$ Peter S Blair, ${ }^{4}$ \\ Peter Fleming ${ }^{4}$
}

\begin{abstract}
- Additional material is published online only. To view please visit the journal online (http://dx.doi.org/10.1136/ archdischild-2014-307908).

${ }^{1}$ Public Health Institute of Mongolia, Ulaanbaatar, Mongolia

${ }^{2}$ Public Health, Epidemiology \& Biostatistics, University of Birmingham, Birmingham, UK ${ }^{3}$ Faculty of Health \& Applied Sciences, University of the West of England, Bristol, UK ${ }^{4}$ School of Social and Community Medicine, University of Bristol, Bristol, UK
\end{abstract}

\section{Correspondence to} Dr Semira Manaseki-Holland, Department of Public Health, Epidemiology and Biostatistics, School of Health and Population Sciences, College of Medical and Dental Sciences, University of Birmingham, Rm G31, Public Health Building, Edgbaston, Birmingham B15 2TT, UK; s.manasekiholland@bham.ac.uk

Received 8 January 2015 Revised 24 September 2015 Accepted 26 September 2015 Published Online First 29 October 2015

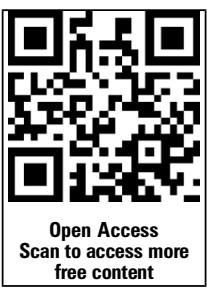

\section{ABSTRACT}

Objective To investigate thermal balance of infants in a Mongolian winter, and compare the effects of traditional swaddling with an infant sleeping-bag in apartments or traditional tents (Gers).

Design A substudy within a randomised controlled trial. Setting Community in Ulaanbaatar, Mongolia.

Subjects A stratified randomly selected sample of 40 swaddled and 40 non-swaddled infants recruited within $48 \mathrm{~h}$ of birth.

Intervention Sleeping-bags and baby outfits of total thermal resistance equivalent to that of swaddled babies. Outcome measure Digital recordings of infants' core, peripheral, environmental and microenvironmental temperatures at 30-s intervals over $24 \mathrm{~h}$ at ages 1 month and 3 months.

Results In Gers, indoor temperatures varied greatly $\left(<0->25^{\circ} \mathrm{C}\right)$, but remained between $20^{\circ} \mathrm{C}$ and $22^{\circ} \mathrm{C}$, in apartments. Despite this, heavy wrapping, bed sharing and partial head covering, infant core and peripheral temperatures were similar and no infants showed evidence of significant heat or cold stress whether they were swaddled or in sleeping-bags. At 3 months, infants in sleeping-bags showed the 'mature' diurnal pattern of a fall in core temperature after sleep onset, accompanied by a rise in peripheral temperature, with a reverse pattern later in the night, just before awakening. This pattern was not related to room temperature, and was absent in the swaddled infants, suggesting that the mature diurnal pattern may develop later in them.

Conclusions No evidence of cold stress was found. Swaddling had no identifiable thermal advantages over sleeping-bags during the coldest times, and in centrally heated apartments could contribute to the risk of overheating during the daytime.

Trial registration number ISRTN01992617.

\section{BACKGROUND}

Swaddling the baby in the cold season is a traditional practice in Mongolia and normally involves tight, prolonged wrapping from the head or neck down in two to three layers of thin cotton cloth, covered by layers of thick blankets or sheepskin (see online supplementary appendix IA). For the first 3 months, the baby is swaddled most of the day and night, with a gradual decrease in intensity and duration of wrapping until beyond 6 months.

Mongolia is a landlocked, East-Asian, developing country of high literacy $(>90 \%)$ and with a population of 2.7 million people, $32 \%$ of whom live below the poverty line. ${ }^{1}$ The climate is dry with extreme temperatures ranging from $-40^{\circ} \mathrm{C}$ in the long winter to $+30^{\circ} \mathrm{C}$ in the summers in Ulaanbaatar.

\section{What is already known on this topic}

Swaddling is widely used in many societies, but little is known about optimal levels of wrapping or the effects on infant thermoregulation.

- Infants can tolerate very wide ranges of added insulation at night, but covering the head can potentially compromise their ability to thermoregulate.

- A number of factors (eg, low birth weight and bottle-feeding) are associated with later development of mature diurnal temperature patterns in infants.

\section{What this study adds}

- Even in extreme environmental conditions swaddling offers no identifiable thermal advantage over the use of baby sleeping-bags.

- Babies living in Gers with extremes of diurnal temperature variation who used sleeping-bags developed mature diurnal temperature patterns earlier than those who were swaddled.

- Swaddled infants showed effective thermoregulation despite very high levels of added insulation, including head covering.

Swaddling is being promoted in many Western countries $^{34}$ as a method of sleep promotion and ensuring supine sleep, while it is practised in many temperate Far-Eastern, Middle-Eastern, Central Asian, former Soviet and South American countries $^{4}$ for practical childcare reasons, protection from cold, and a belief in a number of effects including the promotion of sleep and calm in babies. In Mongolian winter, given the low temperatures, swaddling could be important to protect infants from cold stress which is a risk factor for respiratory infection, ${ }^{5}$ but little is known of any effects of swaddling on thermoregulation in infancy in any environmental condition. This could be important in many ways including as a contributor to Sudden Infant Death Syndrome (SIDS) or respiratory infections in infants.

The majority of the population in Mongolia and almost half of the capital city Ulaanbaatar's one million residents occupy traditional dwellings, the 'Ger' (see online supplementary appendix IC). Temperatures within the Ger vary widely in the 
winter, being very warm in the daytime and very cold at night. Other residents of Ulaanbaatar live in relatively modern centrally heated apartments, connected to a centralised heating system that maintains relatively constant indoor temperatures.

We investigated in a randomised controlled trial (RCT) the effect of swaddling on a range of thermal recordings during a Mongolian winter, and compared the effects of swaddling with a combination of clothing and sleeping-bags designed to be of equal thermal resistance. A secondary objective was to investigate the effect of housing type (and therefore environmental temperature variations) upon this effect.

\section{METHODS}

Sample

This study was nested in a larger prospective RCT designed to investigate the effects of traditional swaddling on pneumonia, health, growth and development of infants in Mongolia. ${ }^{6}$ The main study involved 1274 healthy infants $\geq 37$ weeks gestation and a birth weight of $>2500 \mathrm{~g}$, born in Ulaanbaatar between September and December 2002. All healthy infants delivered at the only four maternity hospitals in Ulaanbaatar, Mongolia were eligible to be recruited within $48 \mathrm{~h}$ of birth (figure 1). More than $95 \%$ of Ulaanbaatar births took place in these four hospitals. ${ }^{7}$ The residents of the town centre apartments known to have very hot indoor central heating were excluded as qualitative work indicated that this interfered with their swaddling patterns. Infants were randomly allocated to swaddled or non-swaddled groups within $48 \mathrm{~h}$ of birth. The two arms had comparable characteristics and randomisation was successful (figure 1).

For the present nested study of detailed recordings, in the peak of winter during December 2002 and March 2003 (therefore selecting babies in November and December), we randomly selected a subset of 40 healthy infants from each arm of the

Figure 1 The trial flow chart.

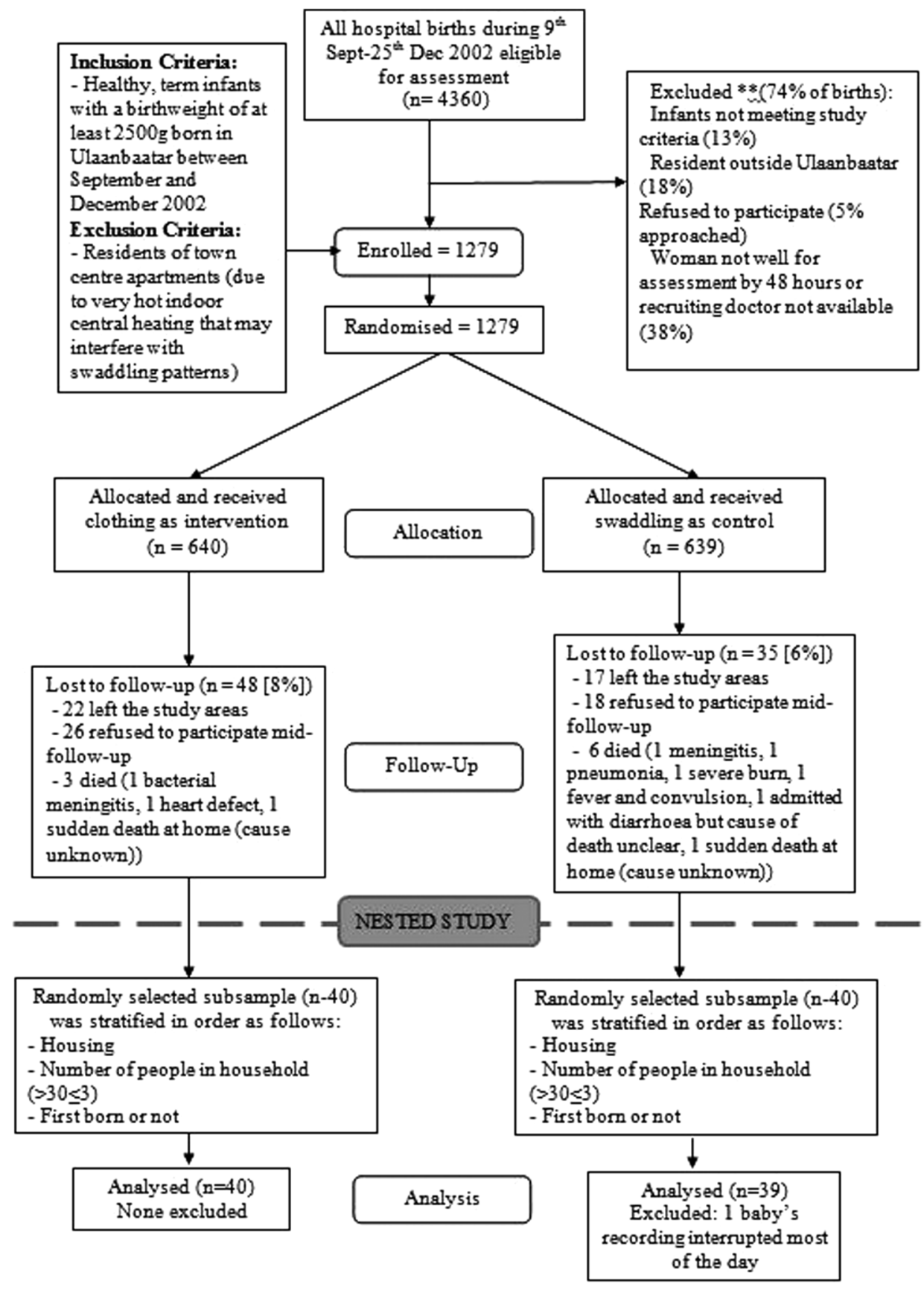


main study stratified by type of dwelling, the number of people living in the household and birth order. After 16 strata were defined, an Excel random number generated list was applied to each stratum and three from each stratum were selected. The infants were those fully compliant to the intervention regimen.

\section{Sample size calculation}

There is little information on the body temperature of swaddled infants in cold environments from previous studies on which to base sample size calculations. The anticipated size of the difference to detect in abdominal skin (core) temperatures between swaddled and infants in sleeping-bags was estimated at $0.5^{\circ} \mathrm{C},{ }^{8-10}$ and the lower and upper ranges of normal abdominal skin temperatures as $36^{\circ} \mathrm{C}$ and $37^{\circ} \mathrm{C}$, respectively, were used. ${ }^{11}$ To detect a $0.5^{\circ} \mathrm{C}$ difference with $95 \%$ confidence at the $5 \%$ significance level with $80 \%$ power the fundamental equation was used. This suggested using at least 17 infants per group or 34 infants as the minimum study sample size. Assuming a $20 \%$ dropout or refusal, 42 infants would be required. However, during the actual study period from 3 December to 26 December, 238 infants reached 1 month of age. Within the resources available, the investigator nearly doubled the sample size of the study to improve estimates and representation of the targeted population.

\section{Intervention}

Families in both groups were asked to cover the baby as they felt was appropriate for the environmental temperature. ${ }^{6}$ Among the swaddled babies (control arm of the trial) the families mostly followed the traditional practice, using cotton and woollen wrapping materials/blankets, together with sheepskins on occasions while in the intervention group they used their own clothes, additional baby clothes and baby sleeping-bags provided for them by the study since non-swaddling options in shops were scarce (see online supplementary appendix 1B). As explained elsewhere, blinding was not possible in such interventions, but thorough compliance monitoring/data is available for each child. ${ }^{6}$ The analysis was blind to allocation.

\section{Measurement of thermoregulation}

Digital recordings of infants' core, peripheral, environmental and microenvironmental temperatures were made on two occasions in the infant's home, each over a $24 \mathrm{~h}$ period: (1) at 1 month and (2) at 3 months of age during the coldest months in the Mongolian year (December-March).

Mothers recorded detailed logs of infant activity and wrapping (including bed sharing adult blankets over the babies at nights) during the recording period using a pretested 24-h diary. They were asked not to bathe the babies in this $24 \mathrm{~h}$ due to the skin probes. Because of the social unacceptability of rectal probes in young infants in Mongolia, we recorded core temperatures using abdominal skin temperature probes over the liver, with insulation over the probe on the surface away from the infant (previously shown to reliably track core temperature). ${ }^{8}{ }^{12}$ For the purposes of comparisons between infants and between sleeping conditions, temperature data were averaged over 15 min periods, each consisting of 30 recorded observations. For the purpose of comparisons between day and night time data we have designated daytime as 9:00 to 21:00, and night-time as 21:00 to 9:00. A temperature data logger (Squirrel) recording at $30 \mathrm{~s}$ intervals on four channels was used to simultaneously record the core body and peripheral (skin of anterior shin) ${ }^{8}$ temperatures, the room temperature (outside all clothing or bedding, but close to infant) and the microenvironmental temperatures in the infant's bedding (inside the sleeping-bag or outer cover or layers of swaddling, but outside the first layers of baby clothing). ${ }^{12}$

\section{Assessment of thermal resistance ('tog values') of bedding and clothing}

Samples were collected of a range of the typical swaddling and clothing materials used and of the infant sleeping-bags produced for the study. At the end of the study direct measurements of the thermal resistance (in tog units) of non-compressed samples of each of these materials were made in the Performance Clothing laboratories of the School of Design in the University of Leeds (Dr David Brook).

We have assumed that the laboratory measurement of thermal resistance is the effective insulation value of each material when in use. In practice the effect of trapped air between layers of bedding or clothing is to increase the insulation values of combinations of materials, but as this variable could not be measured and is likely to be similar between groups we have not taken it into account in our calculations of total insulation levels.

Thermal resistance was calculated using these laboratorymeasured values applied to the detailed maternal logs of the infants' bedding and clothing materials (including head covering). The total effective insulation (in tog units) was calculated by summing the individual contributions from each item of clothing/swaddling and bedding applied, corrected for the proportion of the surface area of the baby that the item covered. ${ }^{8} 1213$

\section{Statistical analysis}

The number of detailed recordings pragmatically possible to collect in such studies is unavoidably limited. We reduced the impact of skewed data by adopting a non-parametrical approach to the analysis. The Mann-Whitney U test (two-sided) was used to compare the differences between distributions.

The $\chi^{2}$ test for independence with Yates' correction was used to test differences between proportions. If an expected cell was below 5 the Fisher's exact test was used. Spearman's rank order correlation (r) was used to calculate the strength of the relationship between continuous variables. ${ }^{14}$

\section{RESULTS}

\section{Background infants' characteristics}

Table 1 describes the family and child characteristics of the sample between 39 swaddled and 40 non-swaddled infants which were equally distributed between the arms. Background characteristics of the sample were comparable with the main study (data not shown). The stratification was successful with no significant differences identified between infants in the swaddling group and the sleeping-bag group for the type of dwelling, number of people in the household or whether the infant was first-born or not. The only baseline variable to significantly differ by chance was birth weight; infants swaddled were slightly but significantly heavier (Mann-Whitney U test: $\mathrm{p}=0.002$ ).

Bed sharing with parents was assessed on two consecutive nights at 1 month and 3 months of age and found to be a universal practice, with no differences between the groups.

\section{Room temperature variation}

The median room temperatures were recorded for each $30 \mathrm{~min}$ period over the $24 \mathrm{~h}$ duration of the recordings at the two ages for infants living in Gers and those living in apartments (see online supplementary appendix II). 
Table 1 Background family and child characteristics; all differences in characteristics between groups are not statistically significant with $p$ values ranging from 0.99 to 0.20 , except birth weight where $p=0.002$

\begin{tabular}{|c|c|c|c|c|}
\hline \multirow[b]{2}{*}{ Background characteristics } & \multicolumn{2}{|c|}{ Swaddling } & \multicolumn{2}{|c|}{ Sleeping-bag } \\
\hline & $\mathbf{n}$ & Per cent & $\mathbf{n}$ & Per cent \\
\hline Total included in analysis & 39 & 100.0 & 40 & 100.0 \\
\hline \multicolumn{5}{|l|}{ Type of dwelling } \\
\hline Ger & 20 & $(52.3)$ & 16 & $(40.0)$ \\
\hline Apartment & 19 & $(47.7)$ & 24 & $(60.0)$ \\
\hline \multicolumn{5}{|c|}{ Number of people in the household } \\
\hline$\leq 3$ people per room & 20 & $(51.3)$ & 22 & $(55.0)$ \\
\hline$>3$ people per room & 19 & $(48.7)$ & 18 & $(45.0)$ \\
\hline \multicolumn{5}{|l|}{ Birth order } \\
\hline First & 18 & $(46.2)$ & 19 & $(48.8)$ \\
\hline Subsequent & 21 & $(53.8)$ & 21 & $(51.2)$ \\
\hline \multicolumn{5}{|l|}{ Gestational age at birth } \\
\hline$<37$ weeks & & - & 3 & $(4.0)$ \\
\hline$\geq 38$ weeks & 39 & (100) & 37 & $(96.0)$ \\
\hline \multicolumn{5}{|l|}{ Type of delivery } \\
\hline Normal vaginal birth & 34 & $(87.2)$ & 30 & $(75.0)$ \\
\hline Caesarean & 3 & (7.7) & 8 & $(20.0)$ \\
\hline Other & 2 & $(5.1)$ & 2 & $(5.0)$ \\
\hline \multicolumn{5}{|l|}{ Gender } \\
\hline Male & 17 & $(42.5)$ & 16 & $(38.5)$ \\
\hline Female & 22 & $(57.5)$ & 24 & $(61.5)$ \\
\hline \multicolumn{5}{|l|}{ Breast feeding after birth } \\
\hline Within $30 \mathrm{~min}$ & 29 & $(78.4)$ & 30 & $(79.0)$ \\
\hline Within $30-60 \mathrm{~min}$ & 6 & $(13.5)$ & 4 & $(5.3)$ \\
\hline Within $24 \mathrm{~h}$ & 4 & $(8.1)$ & 6 & $(15.7)$ \\
\hline \multicolumn{5}{|l|}{ Breast feeding at 1 month } \\
\hline Yes & 38 & $(97.5)$ & 38 & $(97.8)$ \\
\hline No & 1 & $(2.5)$ & 2 & $(2.2)$ \\
\hline \multicolumn{5}{|l|}{ Breast feeding at 3 months } \\
\hline Yes & 36 & $(90.0)$ & 37 & $(94.9)$ \\
\hline No & 3 & $(10.0)$ & 3 & $(5.1)$ \\
\hline \multicolumn{5}{|l|}{ Bed sharing at 1 month } \\
\hline With one adult & 30 & $(79.5)$ & 26 & (65) \\
\hline With two adults & 10 & $(20.5)$ & 14 & (35) \\
\hline \multicolumn{5}{|l|}{ Bed sharing at 3 months } \\
\hline With one adult & 26 & $(66.7)$ & 22 & (55) \\
\hline With two adults & 13 & $(33.3)$ & 18 & $(45)$ \\
\hline \multicolumn{5}{|l|}{ Maternal age at recruitment } \\
\hline 20-29 years & 26 & 66.7 & & \\
\hline$\geq 30$ years & 13 & 33.3 & & \\
\hline \multicolumn{5}{|l|}{ Maternal marital status } \\
\hline Married & 20 & 52.6 & & \\
\hline Cohabiting & 18 & 47.4 & & \\
\hline \multicolumn{5}{|l|}{ Maternal education } \\
\hline Primary and secondary & 16 & 41.0 & & \\
\hline Tertiary & 23 & 59.0 & & \\
\hline Paternal education & & & & \\
\hline Primary and secondary & 23 & 62.9 & & \\
\hline Tertiary & 13 & 37.1 & & \\
\hline Father ever worked & & & & \\
\hline Yes & 31 & 79.5 & & \\
\hline No & 8 & 20.5 & & \\
\hline Smokers resident in home & & & & \\
\hline None & 19 & 48.7 & & \\
\hline One or more & 21 & 51.3 & & \\
\hline & Median & IQR & Median & IQR \\
\hline Birth weight $(\mathrm{kg})$ & 3.6 & $3.2-3.9$ & 3.3 & $3.1-3.5$ \\
\hline Length $(\mathrm{cm})$ & 51 & $50-52$ & 51 & $50-52$ \\
\hline
\end{tabular}

The room temperature in the apartments varied very little over the $24 \mathrm{~h}$ period, staying between $20^{\circ} \mathrm{C}$ and $22^{\circ} \mathrm{C}$ for almost the whole time, a similar range to that previously published for infant homes in the UK. ${ }^{13}{ }^{15}$ In Gers the median room temperatures recorded varied considerably over each $24 \mathrm{~h}$ period (from $13^{\circ} \mathrm{C}$ to $21^{\circ} \mathrm{C}$ ) while individual indoor temperatures ranged from below $0^{\circ} \mathrm{C}$ in the early morning, rising to above $25^{\circ} \mathrm{C}$ in the late afternoon (see online supplementary appendix II).

\section{Thermal insulation}

The median total effective insulation levels (tog values) for bedding and clothing during night-time and daytime were consistently higher for swaddled infants than for those in sleeping-bags regardless of whether the infants slept in Gers or apartments (see online supplementary appendix III).

Similar differences were noted at 3 months of age. The total effective insulation from bedding and clothing was higher for swaddled infants during the night than infants in sleeping-bags in both types of dwelling (higher by 3 togs in Gers and 1.9 togs in apartments, Mann-Whitney $U$ test: $p<0.0001)$. The differences in the day time were much smaller and non-significant (0.3 tog difference in Gers).

This total thermal resistance of bedding plus clothing for the swaddled infants being significantly higher than for nonswaddled infants (table 2) at 1 month and 3 months was reflected in the higher microenvironmental temperatures (inside the bedding but outside the clothing) of the swaddled versus non-swaddled infants in both periods (table 2).

\section{Infants' temperatures at 1 month}

No harmful effects resulting from the intervention were detected by the researchers or the trial monitoring committee. Table 3 shows the median values over the $12 \mathrm{~h}$ daytime and night-time periods for environmental and infant temperatures of 1-month-old infants in Gers and in apartments, respectively.

When viewed over the whole of these $12 \mathrm{~h}$ periods, in the night-time, there were no significant differences in median core or peripheral temperatures between swaddled infants and those in sleeping-bags in either Gers or apartments (tables 3 and 4). Overall in $24 \mathrm{~h}$ (table 2), the core body temperature was also slightly but significantly higher in the swaddled group at $1 \mathrm{~m}$. Despite these differences, however, the peripheral temperatures of the non-swaddled infants (a marker of peripheral vasoconstriction in response to cold stress) were not lower than those of the swaddled infants, suggesting that both groups of infants were in thermoneutral conditions.

The only factor that was not balanced between the swaddling and the sleeping-bag groups was the birth weight of the study babies (table 1). Although all of the infants in this study had birth weights of more than $2500 \mathrm{~g}$, swaddled infants were significantly (median $300 \mathrm{~g}$ ) heavier than the infants in sleepingbags. Thus, this factor was further taken into account in the analysis. Bivariate correlations between birth weight and key temperatures for all infants (swaddled and sleeping-bag together) were all non-significant. Core and peripheral temperatures (24 h, day or night measurements) assessed against birth weight using Spearman's correlation coefficients (coefficients between 0.05 and -0.22 , with values between 0.21 and 0.77 ) indicated that birth weight had no demonstrable relationship with infant body temperatures and, consequently, birth weight variation was unlikely to explain any temperature differences determined.

However, the microenvironmental temperatures (ie, temperatures outside the baby's clothing but inside the bedding) were 
Table 2 The overall 24-h median temperatures for 1-month-old and 3-month-old infants separately

\begin{tabular}{|c|c|c|c|c|c|c|c|c|c|c|}
\hline \multicolumn{6}{|l|}{ One-month-old } & \multicolumn{5}{|c|}{ Three-months-old } \\
\hline \multirow{2}{*}{$\begin{array}{l}\text { Temperature/total } \\
\text { togs }\end{array}$} & \multicolumn{2}{|c|}{ Swaddled ( $n=39$ ) } & \multicolumn{2}{|c|}{ Sleeping-bag $(n=40)$} & \multirow{2}{*}{$\begin{array}{l}\text { Mann-Whitney } \\
\text { U test }\end{array}$} & \multicolumn{2}{|c|}{ Swaddled ( $n=39$ ) } & \multicolumn{2}{|c|}{ Sleeping-bag $(n=40)$} & \multirow{2}{*}{$\begin{array}{l}\text { Mann-Whitney } \\
\text { U test }\end{array}$} \\
\hline & Median & IQR & Median & IQR & & Median & IQR & Median & IQR & \\
\hline Room & 19.0 & $(16.8-21.7)$ & 21.1 & $(18.1-22.4)$ & 0.07 & 20.5 & $(18.4-21.6)$ & 20.8 & $(17.8-22.8)$ & 0.34 \\
\hline Peripheral & 34.9 & (34.4-35.7) & 34.7 & $(33.5-35.2)$ & 0.17 & 28.6 & $(27.2-29.7)$ & 29.3 & $(27.7-30.4)$ & 0.04 \\
\hline Core & 36.9 & $(36.5-37.1)$ & 36.7 & $(36.5-36.9)$ & 0.043 & 36.1 & $(35.9-36.7)$ & 36.0 & $(35.7-36.4)$ & 0.06 \\
\hline Microenvironment & 35.7 & $(35.7-35.9)$ & 35.3 & $(34.7-35.6)$ & 0.008 & 34.8 & (33.9-35.1) & 34.3 & (33.8-34.8) & 0.009 \\
\hline
\end{tabular}

Shading shows statistically significant results.

slightly but significantly higher in the apartments for swaddled infants, partly reflecting the higher insulation used for these babies (13 vs 9.7 median tog in apartment).

When the median temperatures were viewed for each sequential $15 \mathrm{~min}$ period, however, a slightly different picture emerged. For much of the night the median core temperatures over this same $24 \mathrm{~h}$ period for 1-month-old infants living in Gers (figure 2 and table 3) were higher for swaddled infants than for those in sleeping-bags, and these differences were more marked in the daytime, when peripheral temperatures were also higher. This was not completely explained by the higher thermal insulation (tog values) among swaddled infants as these differences in core temperature were not seen in infants sleeping in apartments despite similar differences in thermal insulation.

\section{Infants' temperatures at 3 months}

Table 4 shows the median values for environmental and infant temperatures over the whole $12 \mathrm{~h}$ daytime and night-time periods at age 3 months in Gers and apartments. As for the results at 1 month, there were no significant differences in room temperature for swaddled infants compared with those in sleeping-bags in Gers or apartments.
In contrast to the findings at 1 month, however, the data from the whole $12 \mathrm{~h}$ daytime periods show no significant differences in the median core, peripheral or microenvironmental temperatures between swaddled infants and those in sleeping-bagseither in Gers or in apartments (tables 2 and 4)

At night however, in Gers, the median night-time core temperatures were higher for swaddled infants, while peripheral temperatures were not significantly different. In apartments there was no difference in core temperatures at night, but peripheral temperatures were higher for infants in sleeping-bags.

Figure $3 \mathrm{~A}$ shows for infants in Gers that when the data are plotted for each consecutive $15 \mathrm{~min}$ period during the night, the median core temperature of infants in sleeping-bags fell (from $36.0^{\circ} \mathrm{C}$ to $35.6^{\circ} \mathrm{C}$ ) around $1 \mathrm{~h}$ after babies were put down to sleep and remained below $36^{\circ} \mathrm{C}$ until shortly before waking at 05:00. An apparent very brief further fall later in the morning-seen in swaddled and sleeping-bag infants-is probably related to the first change of nappy/clothing of infants usually occurring around the same time in most families thus accumulating to a dip in the average of recordings. The overnight fall in core temperature was not correlated with changes in room temperature during this period (Spearman'

Table 3 Daytime and night-time median temperatures and total tog measurements of 1-month-old infants in Gers and apartments

\begin{tabular}{|c|c|c|c|c|c|c|c|c|c|c|}
\hline \multicolumn{11}{|c|}{ One-month-old infants in Gers } \\
\hline \multicolumn{6}{|l|}{ Daytime } & \multicolumn{5}{|c|}{ Night-time } \\
\hline \multirow[b]{2}{*}{ Temperature/total togs } & \multicolumn{2}{|c|}{ Swaddled $(n=20)$} & \multicolumn{2}{|c|}{ Sleeping-bag $(n=16)$} & \multirow{2}{*}{$\begin{array}{l}\text { Mann-Whitney } \\
U \text { test } p \text { value }\end{array}$} & \multicolumn{2}{|c|}{ Swaddled $(n=20)$} & \multicolumn{2}{|c|}{ Sleeping-bag $(n=16)$} & \multirow{2}{*}{$\begin{array}{l}\text { Mann-Whitney } \\
U \text { test } p \text { value }\end{array}$} \\
\hline & Median & IQR & Median & IQR & & Median & IQR & Median & IQR & \\
\hline Room & 18.7 & $(17.0-20.1)$ & 18.2 & $(16.8-19.2)$ & 0.57 & 15.0 & $(13.3-17.7)$ & 16.3 & $(13.5-18.3)$ & 0.67 \\
\hline Peripheral & 35.0 & $(34.3-35.2)$ & 33.7 & $(32.6-34.5)$ & $<0.001$ & 35.1 & $(34.8-35.6)$ & 35.0 & $(33.5-35.4)$ & 0.19 \\
\hline Core & 37.0 & $(36.7-37.1)$ & 36.3 & $(36.1-36.6)$ & 0.006 & 36.8 & $(36.6-37.0)$ & 36.7 & $(36.3-36.7)$ & 0.05 \\
\hline Microenvironment & 35.2 & $(34.5-35.8)$ & 34.0 & $(33.3-34.7)$ & 0.009 & 35.8 & $(35.0-36.1)$ & 35.7 & $(34.8-36.1)$ & 0.52 \\
\hline Togs & 8.5 & $(7.6-11.0)$ & 6.4 & $(6.0-7.2)$ & $<0.0001$ & 13.2 & $(11.1-14.6)$ & 9.3 & $(7.3-12.0)$ & $<0.0001$ \\
\hline \multicolumn{11}{|c|}{ One-month-old infants in apartments } \\
\hline \multicolumn{6}{|l|}{ Daytime } & \multicolumn{5}{|c|}{ Night-time } \\
\hline \multirow[b]{2}{*}{ Temperature/total togs } & \multicolumn{2}{|c|}{ Swaddled ( $n=19$ ) } & \multicolumn{2}{|c|}{ Sleeping-bag $(n=24)$} & \multirow{2}{*}{$\begin{array}{l}\text { Mann-Whitney } \\
\mathrm{U} \text { test } \mathrm{p} \text { value }\end{array}$} & \multicolumn{2}{|c|}{ Swaddled ( $n=19$ ) } & \multicolumn{2}{|c|}{ Sleeping-bag $(n=24)$} & \multirow{2}{*}{$\begin{array}{l}\text { Mann-Whitney } \\
\mathrm{U} \text { test } \mathrm{p} \text { value }\end{array}$} \\
\hline & Median & IQR & Median & IQR & & Median & IQR & Median & IQR & \\
\hline Room & 21.8 & $(19.2-22.6)$ & 21.8 & $(20.3-22.7)$ & 0.65 & 21.0 & $(20.0-22.5)$ & 21.7 & $(19.7-23.4)$ & 0.46 \\
\hline Peripheral & 33.8 & $(32.7-34.9)$ & 34.3 & $(33.3-35.0)$ & 0.40 & 34.4 & $(33.8-35.0)$ & 35.1 & $(34.1-35.4)$ & 0.89 \\
\hline Core & 36.7 & $(36.4-37.0)$ & 36.6 & $(36.0-36.9)$ & 0.65 & 36.8 & $(36.4-37.0)$ & 36.8 & $(36.5-37.0)$ & 0.17 \\
\hline Microenvironment & 35.1 & $(34.4-35.6)$ & 34.9 & $(34.2-35.3)$ & 0.12 & 35.8 & $(35.5-36.1)$ & 35.5 & $(35.1-35.9)$ & 0.04 \\
\hline Togs & 8.0 & $(7.0-10.7)$ & 6.5 & $(5.6-7.9)$ & $<0.0001$ & 13.0 & $(8.7-14.4)$ & 9.7 & $(7.9-12.2)$ & $<0.0001$ \\
\hline
\end{tabular}

Shading shows statistically significant results. 
Table 4 Daytime and night-time median temperatures of 3-month-old infants in Gers and apartments

\begin{tabular}{|c|c|c|c|c|c|c|c|c|c|c|}
\hline \multicolumn{11}{|c|}{ Three-month-old infants in Gers } \\
\hline \multicolumn{6}{|l|}{ Daytime } & \multicolumn{5}{|c|}{ Night-time } \\
\hline \multirow[b]{2}{*}{ Temperature/total togs } & \multicolumn{2}{|c|}{ Swaddled $(n=20)$} & \multicolumn{2}{|c|}{ Sleeping-bag $(n=16)$} & \multirow{2}{*}{$\begin{array}{l}\text { Mann-Whitney } \\
\text { U test } p \text { value }\end{array}$} & \multicolumn{2}{|c|}{ Swaddled $(n=20)$} & \multicolumn{2}{|c|}{ Sleeping-bag $(n=16)$} & \multirow{2}{*}{$\begin{array}{l}\text { Mann-Whitney } \\
\mathrm{U} \text { test } \mathrm{p} \text { value }\end{array}$} \\
\hline & Median & IQR & Median & IQR & & Median & IQR & Median & IQR & \\
\hline Room & 19.2 & $(17.5-21.8)$ & 19.2 & $(18.4-22.9)$ & 0.48 & 16.6 & $(12.6-18.6)$ & 17.8 & $(12.5-19.4)$ & 0.62 \\
\hline Peripheral & 28.1 & $(28.0-30.0)$ & 29.3 & $(27.4-32.0)$ & 0.58 & 30.0 & $(28.4-31.0)$ & 31.0 & $(30.0-32.0)$ & 0.18 \\
\hline Core & 36.3 & $(36.0-36.5)$ & 36.0 & $(35.3-36.3)$ & 0.10 & 36.4 & $(36.2-36.9)$ & 36.0 & $(35.5-36.3)$ & 0.02 \\
\hline Microenvironment & 34.5 & $(33.3-34.8)$ & 33.8 & $(33.7-34.3)$ & 0.20 & 35.2 & $(34.9-35.8)$ & 34.9 & $(34.0-35.2)$ & 0.05 \\
\hline Togs & 10 & $(9.0-11.2)$ & 9.7 & $(7.1-11.6)$ & 0.12 & 13.2 & $(10.4-16.0)$ & 10.2 & $(9.5-12.0)$ & $<0.0001$ \\
\hline \multicolumn{11}{|c|}{ Three-month-old infants in apartments } \\
\hline \multicolumn{6}{|l|}{ Daytime } & \multicolumn{5}{|c|}{ Night-time } \\
\hline \multirow[b]{2}{*}{ Temperature/total togs } & \multicolumn{2}{|c|}{ Swaddled $(n=19)$} & \multicolumn{2}{|c|}{ Sleeping-bag $(n=24)$} & \multirow{2}{*}{$\begin{array}{l}\text { Mann-Whitney } \\
\text { U test } p \text { value }\end{array}$} & \multicolumn{2}{|c|}{ Swaddled $(n=19)$} & \multicolumn{2}{|c|}{ Sleeping-bag $(n=24)$} & \multirow{2}{*}{$\begin{array}{l}\text { Mann-Whitney } \\
\mathrm{U} \text { test } \mathrm{p} \text { value }\end{array}$} \\
\hline & Median & IQR & Median & IQR & & Median & IQR & Median & IQR & \\
\hline Room & 21.5 & $(20.1-22.1)$ & 21.7 & (20.7-23.3) & 0.19 & 21.3 & $(20.1-22.1)$ & 22.1 & $(19.8-22.6)$ & 0.29 \\
\hline Peripheral & 29.0 & (27.3-29.2) & 29.0 & $(29.0-30.0)$ & 0.09 & 29.3 & $(28.0-31.0)$ & 31.1 & $(29.2-33.0)$ & 0.03 \\
\hline Core & 36.0 & $(35.8-36.4)$ & 36.1 & $(35.7-36.3)$ & 0.98 & 36.0 & $(35.8-36.3)$ & 36.2 & $(35.6-36.5)$ & 0.83 \\
\hline Microenvironment & 34.2 & $(33.6-34.9)$ & 34.1 & $(33.0-34.5)$ & 0.33 & 35.0 & $(34.8-35.5)$ & 35.0 & $(34.4-35.2)$ & 0.37 \\
\hline Togs & 9.4 & $(7.9-10.5)$ & 8.9 & $(6.4-9.7)$ & $<0.0001$ & 11.5 & $(8.9-13.2)$ & 9.6 & $(8.9-12.0)$ & $<0.0001$ \\
\hline
\end{tabular}

$\mathrm{r}=0.18, \mathrm{p}=0.54$ ), but was similar to the pattern previously described in healthy 3-4-month-old infants. ${ }^{15-19}$ Strikingly, this nocturnal fall in core body temperature was absent in swaddled infants.

Figure 3B shows the corresponding diurnal pattern seen when the values of median peripheral temperature from sequential $15 \mathrm{~min}$ periods for these infants are plotted. Despite the observed lower core temperature during the night-time hours, for infants in sleeping-bags their peripheral temperatures were consistently slightly higher than for those who were swaddled. This is evidence of peripheral vasodilatation in the infants in sleeping-bags, not vasoconstriction, as would occur if the observed lower core temperatures were a consequence of cold stress.

In contrast, no such differences between core temperatures of swaddled infants and those using sleeping-bags were observed for 3-month-old infants living in apartments (figure 3C). There was no drop in core temperature observed for 3-month-old infants in sleeping-bags living in apartments at nights. However, the peripheral temperatures of these infants were consistently $1-3^{\circ} \mathrm{C}$ higher than for swaddled infants during the night-time (figure $3 \mathrm{D}$ ), again showing evidence of peripheral vasodilatation

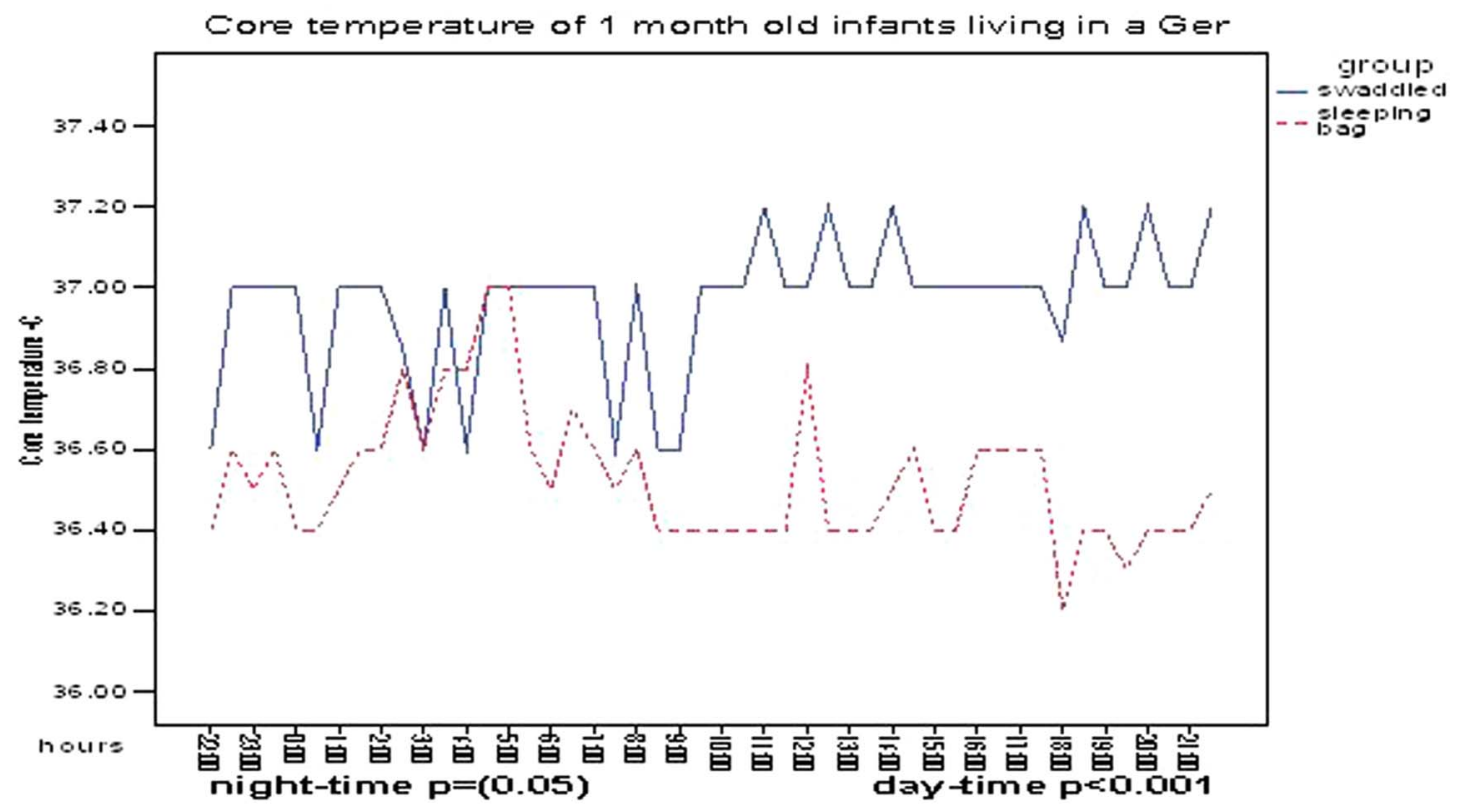

Figure 2 Diurnal core temperature patterns (median values) for swaddled and sleeping-bag infants living in Gers at age 1 month. 

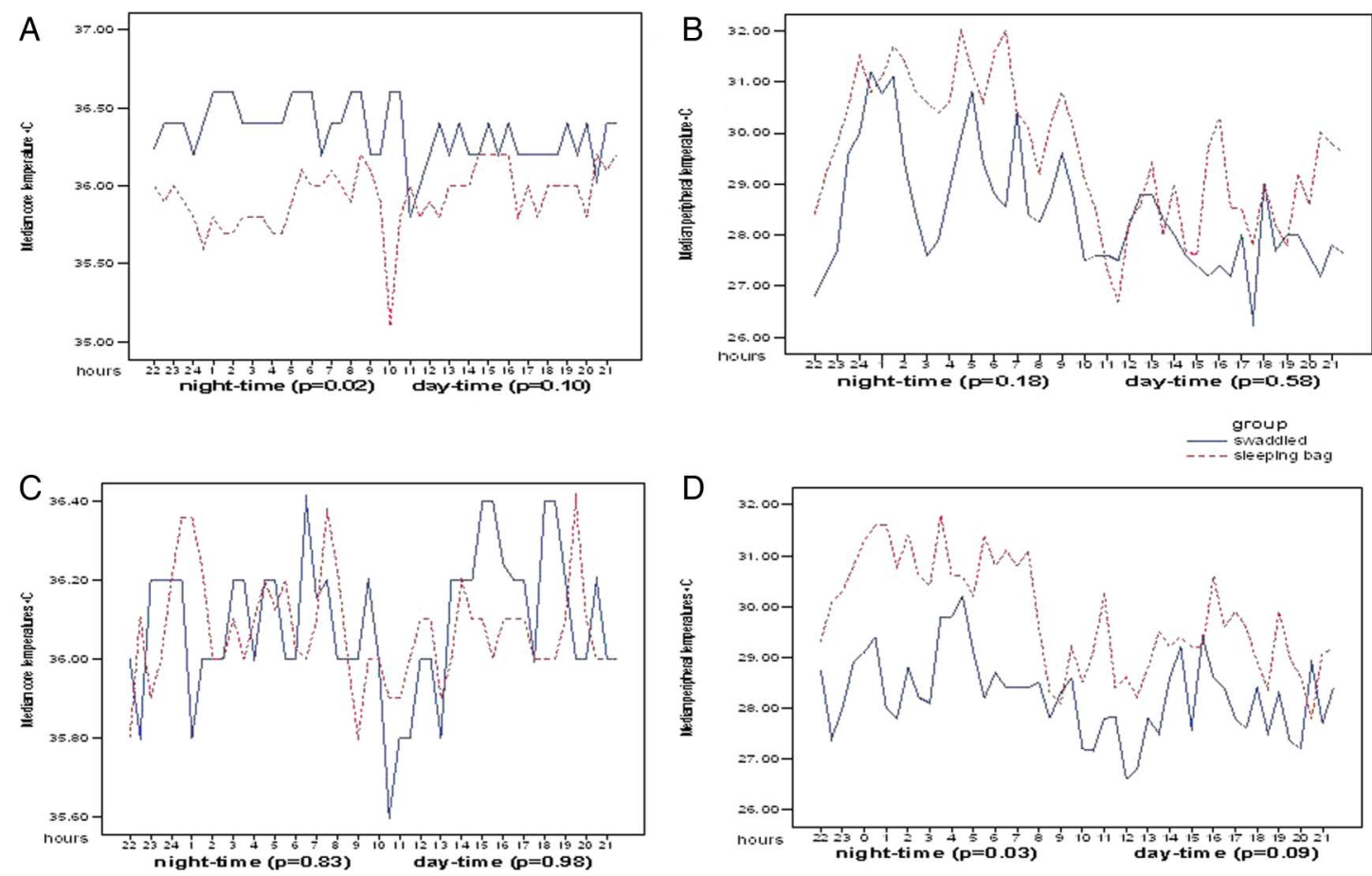

Figure 3 Diurnal core temperatures (median values) for swaddled and sleeping-bag infants in: (A) Gers and (C) apartments at age 3 months; and diurnal peripheral temperatures (median values) for swaddled and sleeping-bag infants in: (B) Gers and (D) apartments at age 3 months.

in this group, despite being significantly less heavily wrapped than the swaddled infants.

\section{DISCUSSION}

This study assessed for the first time the effects of traditional swaddling and the use of sleeping-bags on infant thermoregulation in non-laboratory conditions in a country with very cold winter months. Despite harsh environmental conditions, heavy wrapping, bed sharing and partial head covering, no infants showed evidence of significant heat or cold stress whether they were swaddled or in sleeping-bags.

Review of the detailed 24-h logs kept by the mothers (numbers of layers and arrangements of clothing and bedding as judged appropriate by mothers) when combined with the subsequent laboratory measurements of thermal resistance of the materials showed that the total thermal resistance of bedding plus clothing for the swaddled infants was significantly higher than for non-swaddled infants at 1 month and 3 months. This was reflected in the higher microenvironmental temperatures (inside the bedding but outside the clothing) of the swaddled versus non-swaddled infants. The core body temperature was also slightly but significantly higher in the swaddled group at 1 month, but not at 3 months of age. Despite these differences, however, the peripheral temperatures of the non-swaddled infants (a marker of peripheral vasoconstriction in response to cold stress) were not lower than those of the swaddled infants, at either age, suggesting that both groups of infants were in thermoneutral conditions. There were no episodes of increased peripheral temperature accompanied by rises in core temperature, which would have been suggestive of heat stress.

Room temperatures recorded in apartments in Ulaanbaatar were similar to those previously reported in the UK. ${ }^{13}{ }^{15-17}$ In a study in Bristol we recorded average indoor temperatures in infants' bedrooms in winter of $18-19^{\circ} \mathrm{C}$, and in the summer of $20-22^{\circ} \mathrm{C},{ }^{13}$ with less than $3^{\circ} \mathrm{C}$ difference between night-time and daytime temperatures, in summer and winter. Mongolian infants living in a Ger experienced greater room temperature variation in 1 day than UK infants experience over the course of a year with minimum temperatures sometimes as low as $0^{\circ} \mathrm{C}$ and maximum temperatures up to $25^{\circ} \mathrm{C}$.

In this extreme environment, potential adverse consequences might have been anticipated, such as hypothermia at night or hyperthermia in the daytime. However, core body temperatures were remarkably similar in traditional Gers and apartments at both ages, whether the infants were swaddled or in sleepingbags. On an individual level there were no recorded episodes of significant hypothermia or hyperthermia (core temperatures below $35^{\circ} \mathrm{C}$ or above $38^{\circ} \mathrm{C}$, respectively).

A marked fall in core temperature during the night-time was observed for 3-month-old infants in sleeping-bags living in Gers. This fall in core temperature at this age is expected ${ }^{16-20}$ and was accompanied by a rise in peripheral temperature, showing that it was not an effect of cold stress (which leads to peripheral vasoconstriction and thus a fall in peripheral temperatures) but rather to the normal process previously reported in infants from around this age: that of active peripheral vasodilatation with increased heat loss leading to a fall in core temperature during the early part of the night-time hours, and with a reversal of this process during the latter part of the night. ${ }^{15-22}$ The indoor temperature fell, but the core temperature fall was independent of the minimum indoor temperature, which commonly occurred at the time core infant temperature was rising. Thus, the greater fall in the core temperature of infants in sleeping-bags reflects the development of a normal diurnal pattern of temperature changes with age. This diurnal pattern of temperature change, exactly as previously described in infants in studies in the UK, ${ }^{15-21} 23$ commonly becoming clearly marked by around 3 months of age, was not seen in this study in infants who were swaddled.

A range of factors, including preterm birth, low birth weight, low Apgar scores and bottle-feeding have been reported to be associated with slightly delayed development of diurnal 
temperature patterns in infancy. ${ }^{15} 2223$ None of these factors were present in our sample of infants and thus cannot explain the differences between the diurnal temperature patterns seen in the infants in the present study who were swaddled compared with those in sleeping-bags. Indeed the median birth weight of the infants in sleeping-bags was by chance $300 \mathrm{~g}$ less than for the swaddled infants, which might have been expected to contribute to later maturation of diurnal temperature pattern in these infants. We found no evidence of a relationship between birth weight and infant temperature in our data.

There were several strengths and weaknesses in our study. The unique set-up of this study enabled investigations into thermal conditions that are difficult to create in the lab or other natural settings. The RCT design of the main study enabled the comparison of similar populations only different in their habitual swaddling or sleeping-bag type of clothing in a powerful study design. The study randomisation process and stratified subsampling ensured that the two study groups (swaddled and sleepingbags) were similar in terms of the type of dwelling, crowding and maternal parity and all other characteristics. Our findings are generalisable to infants born healthy in Ulaanbaatar as the mothers were representative of the greater population, and in fact of all such healthy-at-birth infants subject to similar environmental and clothing conditions since this cohort of Mongolian infants were not exposed to other unusual circumstances. However, the small numbers involved in this thermoregulatory study did not enable multivariate analysis investigating other influences on thermoregulation in this population.

We tried to ensure that all infants were wrapped in bedding and clothing of similar total thermal resistance ('tog values'), but were not entirely successful as the choice of clothing was left ultimately to the parents. The clothing plus sleeping-bags used were designed to be of approximately equal thermal resistance to the commonly used swaddling materials; and the study provided an opportunity to evaluate this low-cost, safe, locally sourced alternative approach to infant insulation and care in this extreme environment. Qualitative data from the study parents indicated that parents of infants using the sleeping-bags tried to create the same level of warmth for their infants with non-swaddling clothes and sleeping-bags/blankets, but their judgements did not match the insulation values they thought swaddling would provide since tog values in swaddled infants were consistently higher (by around 4 togs). We have previously shown that parents are skilled at achieving appropriate levels of added bedding and clothing to avoid cold stress, ${ }^{13}$ and this study confirms this observation-even in the extreme climate of Mongolia.

Total thermal resistance during the night-time was consistently 2-5 togs higher than during the daytime at both ages. This is in general agreement with other studies that infants were kept warmer during the night. ${ }^{13} 151620$ Despite heavy insulation, swaddling offered no identifiable thermal advantage or disadvantage to the baby over the use of a sleeping-bag at night.

Additionally, traditional sleeping arrangements certainly contributed to higher thermal insulation at night. Ninety-eight percent of infants slept in bed with one or both parents, under the parents' bedding as well as the sleeping-bags or swaddling. It is possible that habitually high levels of insulation, with consequently much higher environmental temperatures for these infants with a higher core temperature in the daytime, may contribute to a delay in the development of the normal overnight fall in core temperature. This phenomenon has not previously been described, but previous studies ${ }^{13-16}$ have used much lower levels of thermal insulation. The present study of infants sleeping in their normal swaddling environment compared with our intervention, identified conditions that were far more extreme than would have been ethical to impose upon infants in an intervention study-either in the home or the laboratory.

Although there was no evidence that individual infants suffered significant cold stress or heat stress the microenvironment around swaddled infants was consistently significantly warmer than for those in sleeping-bags.

In conclusion, this study is unique in investigating infants' thermal balance during early infancy, in naturalistic settings and in a very cold indoor environment, where traditional practices are well represented and within a culture in which studies have not previously been conducted. Furthermore, the study addresses a very important issue (temperature maintenance) in the care of infants in a harsh climate, in Mongolia and in many low-income and middle-income countries where traditional swaddling remains a central infant care practice, commonly interacting with changing housing arrangements.

Overall, there is evidence that traditional Mongolian swaddling of healthy infants is not associated with identifiable thermal disadvantages or advantages at 1 month and 3 months of age. It seems however that, for swaddled infants in apartments, less wrapping may be needed.

The observed differences in the development of the nocturnal fall in core temperature between swaddled infants and those in sleeping-bags gives an interesting insight into developmental physiology. The significance of the wide normal variation in the development of this pattern is not known but might stimulate further research.

Acknowledgements The authors thank the families who took part in this study, the extensive staff of main trial, Project Manager Dr N Gombjav, Prof Choijamts the local sponsor and director of the Project Hospital, Dr Soyolgerel at the Ministry of Health in Mongolia, for data for this study. The authors also thank Dr Brook.

Contributors The following authors have contributed to the article as described: $\mathrm{SM}-\mathrm{H}$ - Trial Director, helped design the substudy, supervised the conduct of the substudy, wrote the drafts of paper for consultation. BT-helped design the substudy, conducted the substudy, analysed the data and contributed to writing the paper. JP-helped design the substudy, supervised the conduct of the substudy and contributed to writing the paper. PSB - supervised and contributed to the analysis and writing of the paper. PF-helped design the substudy, supervised the conduct of the substudy, wrote the first drafts of the paper. All authors contributed to and approved the final draft of the paper.

Funding The donors for this project were the Wellcome Trust.

Disclaimer The study sponsors did not have any role in the study design, in the collection, analysis and interpretation of the data; in the writing of the report and in the decision to submit the paper for publication.

Competing interests None declared.

Patient consent Obtained.

Ethics approval Research Ethics Committees of the Ministry of Health of Mongolia and the London School of Tropical Medicine and Hygiene.

Provenance and peer review Not commissioned; externally peer reviewed.

Open Access This is an Open Access article distributed in accordance with the terms of the Creative Commons Attribution (CC BY 4.0) license, which permits others to distribute, remix, adapt and build upon this work, for commercial use, provided the original work is properly cited. See: http://creativecommons.org/ licenses/by/4.0/

\section{REFERENCES}

1 Implementing Agency of the Government of Mongolia. Department of Health, Health Indicators. 2009.

2 National Statistical Office, World Bank, UNDP, Mongolia. Main report of "Household income and expenditure survey/Living standard measurement survey". Ulaanbaatar, Mongolia: National Statistical Office, 2004.

3 Franco P, Seret N, Van Hees J, et al. Influence of swaddling on sleep and arousal characteristics of healthy infants. Pediatrics 2005;115:1307-11. 
4 Gerard CM, Harris KA, Thach BT. Physiologic studies on swaddling: an ancient child care practice, which may promote the supine position for infant sleep. J Pediatr 2002;141:398-404.

$5 \mathrm{Xu} \mathrm{Z}$, Etzel RA, Su H, et al. Impact of ambient temperature on children's health: a systematic review. Environ Res 2012;117:120-31.

6 Manaseki-Holland S, Spier E, Bavuusuren B, et al. Effects of traditional swaddling on development: a randomized controlled trial. Pediatrics 2010;126:e1485-92.

7 World Health Organisation, Government of Mongolia. Mongolia health sector review (HSR). Ulaanbaatar: WHO and the Government of Mongolia, 1999.

8 Azaz $Y$, Fleming PJ, Levine $M$, et al. The relationship between environmental temperature, metabolic rate, sleep state, and evaporative water loss in infants from birth to three months. Pediatr Res 1992;32:417-23.

9 Baddock SA, Galland BC, Beckers MG, et al. Bed-sharing and the infant's thermal environment in the home setting. Arch Dis Child 2004;89:1111-16.

10 Tuffnell CS, Peterson SA, Wailoo MP. Higher rectal temperature in co-sleeping infants. Arch Dis Child 1996;75:249-50.

11 Thomas K. Thermoregulation in neonates. Neonatal Netw 1994;13:15-22.

12 Arkell S, Blair P, Henderson J, et al. Is the mattress important in helping babies keep warm?-Paradoxical effects of a sleeping surface with negligible thermal resistance. Acta Paediatrica 2007;96:199-205.

13 Wigfield RE, Fleming PJ, Azaz YEZ, et al. How much wrapping do babies need at night. Arch Dis Child 1994;69:1871-186.
14 Siegel S, Castellan NJJ. Non-parametric statistic for behavioural sciences. 2nd edn. McGraw-Hill International, 1988.

15 Lodemore M, Petersen SA, Wailoo MP. Development of night time temperature rhythms over the first six months of life. Arch Dis Child 1991;66:521-4.

16 Wailoo MP, Petersen SA, Whittaker $\mathrm{H}$, et al. The thermal environment in which 3-4 month old infants sleep at home. Arch Dis Child 1989;64:600-4.

17 Wailoo MP, Petersen SA, Whittaker $\mathrm{H}$, et al. Sleeping body temperatures in 3-4 months old infants. Arch Dis Child 1990;64:596-9.

18 Fleming P, Young J, Blair P. The importance of mother-baby interactions in determining night time thermal conditions for sleeping infants: observations from the home and sleep laboratory. Paediatr Child Health 2006;11(Suppl):7A-11A.

19 Lodemore MR, Petersen SA, Wailoo MP. Factors affecting the development of night time temperature rhythms. Arch Dis Child 1992;67:1259-61.

20 Tappin DM, Ford RP, Price B, et al. Overnight central and peripheral temperature changes in normal infants. Acta Paediatrica 2003;92:1003-6.

21 Fleming PJ, Howell T, Clements $M$, et al. Thermal balance and metabolic rate during upper respiratory tract infection in infants. Arch Dis Child 1994;70:187-91.

22 Petersen SA, Wailoo MP. Interactions between infant care practices and physiological development in Asian infants. Early Hum Dev 1994;38:181-6.

23 Wailoo MP, Westaway JA, Joseph $\mathrm{D}$, et al. Overnight deep body temperature and urinary cortisol excretion in infants from economically deprived areas. Child Care Health Dev 2003;29:473-80. 